\title{
Raman Spectroscopic Study on Alkaline Metal Ion Solvation in 1-Butyl-3-methylimidazolium Bis(trifluoromethanesulfonyl)amide Ionic Liquid
}

\author{
Yasuhiro Umebayashi, *† Taishi YamaguchI, ${ }^{*}$ Shuhei Fukuda,* Takushi Mitsugi,* \\ Munetaka TAKEUCHI,* Kenta FuJII,** and Shin-ichi ISHIGURO* \\ *Department of Chemistry, Faculty of Science, Kyushu University, Hakozaki, Higashi, Fukuoka 812-8581, Japan \\ **Department of Chemistry and Applied Chemistry, Faculty of Science and Engineering, Saga University, \\ Honjo-machi, Saga 840-8502, Japan
}

\begin{abstract}
The Raman spectra for 1-butyl-3-methylimidazolium bis(trifluoromethanesulfonyl)amide [BMI][TFSA] containing alkaline metal salts of TFSA ${ }^{-}$, MTFSA $(\mathrm{M}=\mathrm{Li}, \mathrm{Na}, \mathrm{K}$ and $\mathrm{Cs})$, were recorded in the frequency range of $200-1800 \mathrm{~cm}^{-1}$, with varying salt concentrations at $298 \mathrm{~K}$. With $\mathrm{Li}^{+}$and $\mathrm{Na}^{+}$ions, at the frequency range of $730-760 \mathrm{~cm}^{-1}$, new Raman bands ascribable to the anion bound to the ions appeared at higher frequency relative to that found in the neat ionic liquid. On the other hand, with $\mathrm{K}^{+}$and $\mathrm{Cs}^{+}$ions, single Raman bands were solely observed. According to the difference Raman spectra for the ionic liquids containing $\mathrm{K}^{+}$and $\mathrm{Cs}^{+}$, evaluated by subtracting Raman spectra for the neat ionic liquid, it turned out that two-state approximation, i.e., bulk TFSA- and TFSA- bound to $\mathrm{K}^{+}$and $\mathrm{Cs}^{+}$ions, could hold, as $\mathrm{Li}^{+}$and $\mathrm{Na}^{+}$ ions. By careful analyses of Raman band intensity arising from bulk TFSA- as a function of the salt concentration, the solvation numbers for the respective ions were successfully evaluated to be 1.95 for $\mathrm{Li}^{+}, 2.88$ for $\mathrm{Na}^{+}, 3.2$ for $\mathrm{K}^{+}$and 3.9 for $\mathrm{Cs}^{+}$, respectively. By taking into account that TFSA- acts as a bidentate ligand, the atomic coordination numbers are proposed to be 4, 6, 6 and 8 for $\mathrm{Li}^{+}, \mathrm{Na}^{+}, \mathrm{K}^{+}$and $\mathrm{Cs}^{+}$, respectively. Raman shifts for the TFSA- bound to the metal ions relative to that of the bulk TFSA- were plotted against the ionic radii for the solvated alkaline metal ions estimated via Shannon's ionic radii, to yield a straight line with a slope of almost unity, suggesting that the electrostatic interaction predominantly operates in the ion-ion interaction between the alkaline metal ions and TFSA-, as expected. Moreover, the Raman spectra in the frequency range of $370-450 \mathrm{~cm}^{-1}$ strongly depend on the alkaline metal ions, indicating that cis TFSA $^{-}$is favored in the first solvation sphere of the $\mathrm{Li}^{+}$ion of a relatively small ionic radius, and that such a preferred conformational isomerism of TFSA- diminishes with an increase of the ionic radii of the central metal ions.
\end{abstract}

(Received June 24, 2008; Accepted July 18, 2008; Published October 10, 2008)

\section{Introduction}

Room temperature ionic liquids have recently attracted much attention as environmentally favorable solvents owing to their practically negligible vapor pressure. The non-volatility, and thus non-flammability of ionic liquids stimulate researchers to develop high-energy density electrochemical devices of high safety, ${ }^{1}$ such as fuel cells, ${ }^{2}$ lithium ion secondary batteries, ${ }^{3}$ electric double-layer capacitors ${ }^{4}$ and dye-sensitized solar cells. ${ }^{5}$ On the other hand, one of the promised applications of ionic liquids is alternative solvents instead of conventional volatile organic solvents for separation and extraction. Some useful reviews on separation and extraction using ionic liquids have been published. ${ }^{6}$ The efforts to develop new ionic liquids for the purpose is still continued. ${ }^{7}$ Though numerous numbers of ionic liquid applications, particularly those using metal ions, as mentioned above, have been published, studies from the viewpoint of fundamental science seem to be scarce in ionic liquid chemistry. Nishi and Kakiuchi et al. successfully applied the ion transfer voltammetry across the electrochemically

$\dagger$ To whom correspondence should be addressed. E-mail: yumescc@mbox.nc.kyushu-u.ac.jp polarized micro liquid-liquid interface between water and ionic liquids, and found that the transfer of alkali metal ions $\left(\mathrm{Li}^{+}, \mathrm{Na}^{+}\right.$, $\mathrm{K}^{+}, \mathrm{Rb}^{+}, \mathrm{Cs}^{+}$) across the interface between an aqueous solution and a highly hydrophobic ionic liquid, $N$-octadecylisoquinoliniumtetrakis[3,5-bis(trifluoromethyl)phenyl]borate ([C18Iq][TFPB]), can be facilitated by dibenzo-18-crown-6 (DB18C6). ${ }^{8}$ They evaluated the formation constants for a complex formation between alkaline metal ions and DB18C6 in the [C18Iq][TFPB] ionic liquid, and found that the ionic liquid provides a unique solvation environment for the complexations of DB18C6 with alkaline metal ions.

As is well established, solvation plays a key role in chemical reactions in solutions particularly ion-pair formation, complex formation and electron-transfer reactions. Therefore, it should be indispensable to reveal solvation in ionic liquids from thermodynamic and structural viewpoints. Hardacre reviewed EXAFS (extended X-ray absorption fine structure) studies on ionic liquids containing metal ions, including those of conventional room temperature molten salts. ${ }^{9}$ On the other hand, structural aspects on alkylimidazolium-based salts containing fluoro-anions have recently been reviewed, while focusing on the solid state. ${ }^{10}$ Jensen et al. reported structures of $\mathrm{Sr}^{2+}$ and $\mathrm{Eu}^{3+}$ complexes in ionic liquids by EXAFS and HES (high-energy X-ray scattering) techniques. ${ }^{11}$ However, little has 
been reported on the "naked" solvation structure of metal ions in ionic liquids, ${ }^{12}$ though those in aqueous and non-aqueous solvents were accumulated. ${ }^{13}$ EXAFS is a useful technique to determine the structural parameters for heavy metal ions, while it is not so easy to apply to prove ions of small atomic number. With regard to alkaline metal ions, a few Raman spectroscopic studies on lithium ion solvation have been published in connection with lithium ion secondary batteries using ionic liquids composed of bis(trifluoromethanesulfonyl)amide. ${ }^{14-16}$ However, the lithium ion solvation number in ionic liquids was not clear, because the Raman spectra for ionic liquids containing lithium ion, and even neat ionic liquids, themselves, are quite complicated, i.e., according to our previous studies, the components 1-ethyl-3-methylimidazolium $\left(\mathrm{EMI}^{+}\right),{ }^{17} \mathrm{~N}$-butyl- $\mathrm{N}$ methylpyrrolidinium $\left(\mathrm{P}_{14^{+}}\right)^{18}$ and bis(trifluoromethanesulfonyl)amide $\left(\mathrm{TFSA}^{-}\right)^{19}$ ions have conformational isomerism, and two or three predominant conformers of the respective ions exist in equilibrium in the corresponding ionic liquids.

Recently, we reported on the lithium ion solvation structure in [EMI][TFSA] and $\left[\mathrm{P}_{14}\right][\mathrm{TFSA}]$ ionic liquids by means of Raman spectroscopy and DFT calculations, ${ }^{20}$ and elucidated that the lithium ion is coordinated by two TFSA- anions as a bidentate ligand, and that the anion in the first coordination sphere of the lithium ion prefers the cis conformation (two $\mathrm{CF}_{3}$ groups locate at the cis position with respect to the $\mathrm{S}-\mathrm{N}-\mathrm{S}$ plane), though the trans one is a slightly favorable isomer in neat ionic liquids. In order to understand the ion-ion interactions for metal ion solvation in ionic liquids in detail, it is needed to reveal the ionic radii dependence of the ion solvation. Thus, we extended our study on the solvation structure of metal ions in ionic liquids to other alkaline metal ions $\left(\mathrm{Na}^{+}, \mathrm{K}^{+}\right.$and $\left.\mathrm{Cs}^{+}\right)$. It should be noted that the ionic radii for the solvated alkaline metal ions can be reasonably specified by knowing the atomic coordination numbers in ionic liquids.

In this paper, the Raman spectra of 1-butyl-3-mehtylimidazolium bis(trifluoromethanesulfonyl)amide [BMI][TFSA] ionic liquid containing alkaline metal salts MTFSA $(\mathrm{M}=\mathrm{Li}, \mathrm{Na}, \mathrm{K}$, and $\mathrm{Cs})$ were recorded with varying the metal ion concentration. The integral intensity of the Raman band for the bulk TFSA ${ }^{-}$anion in the respective metal ion solution was quantitatively analyzed as a function of the metal ion concentration. The solvation numbers for the alkaline metal ions in the ionic liquid were successfully evaluated. The ion-ion interactions between TFSA ${ }^{-}$ and the alkaline metal ions were discussed in terms of the dependence of the $\Delta v$ values $\left(\Delta v=v_{\mathrm{M}}-v_{\text {bulk }}, v_{\mathrm{M}}\right.$ and $v_{\text {bulk }}$ stand for the peak positions for the Raman bands arising from TFSA bound to the alkaline metal ion and the bulk one, respectively) on the ionic radii of the solvated metal ions. Moreover, we found that the anion conformations in the first solvation spheres of the metal ions depend on the ionic radii of the central alkaline metal ions. The conformations of the anion bound to the alkaline metal ions are also discussed with the aid of MD simulations for similar systems.

\section{Experimental}

\section{Materials}

LiTFSA and KTFSA salts (Morita Chemical Industries) dried in vасио at $423 \mathrm{~K}$ for $48 \mathrm{~h}$ were used without further purification. NaTFSA and CsTFSA salts were prepared by treating the corresponding carbonates with an aqueous solution of HTFSA (Morita Chemical Industries), and recrystallized 3 times from water, then dried in vacuo at $423 \mathrm{~K}$ for $48 \mathrm{~h}$. The solvent $[\mathrm{BMI}][\mathrm{TFSA}]$ was obtained by treating $[\mathrm{BMI}][\mathrm{Br}]$ with an HTFSA aqueous solution, followed by repeated recrystallization from water and drying in vасио at $348 \mathrm{~K}$. The residual $\mathrm{Br}$ was checked to be negligible by the $\mathrm{AgNO}_{3}$ test. $[\mathrm{BMI}][\mathrm{Br}]$ was synthesized according to the literature from $N$-methylimidazole (Nippon Synthetic Chemical Industry) and bromobutane (Tokyo Chemical Industry), which were distilled in advance. ${ }^{21}$ The water content was checked by a Karl Fischer method to be below $100 \mathrm{ppm}$ for all samples examined. Sample solutions were prepared by dissolving a given amount of the alkaline metal salts in the ionic liquid [BMI][TFSA] at ambient temperature. All samples used in this study were treated and stored in a high-performance glove box (Miwa), in which the water and oxygen contents were kept below $1 \mathrm{ppm}$.

\section{Raman spectra measurements}

Raman spectra were obtained using an FT-Raman spectrometer (Perkin Elmer GX-R) equipped with an Nd:YAG laser operating at $1064 \mathrm{~nm}$. The laser power was kept at 800 $\mathrm{mW}$ throughout measurements. The optical resolution was 2.0 $\mathrm{cm}^{-1}$ and spectral data were accumulated 1024 times to obtain data of a sufficiently high signal-to-noise ratio. The sample liquid in a quartz cell was stirred and thermostated at a given temperature within $\pm 0.3 \mathrm{~K}$. No appreciable damage to the sample was detected after irradiation. The measured Raman intensities were normalized using the $826 \mathrm{~cm}^{-1}$ band ascribable to $\mathrm{BMI}^{+}, 22$ and the concentrations of ions in sample liquids were corrected for the density. The densities of sample solutions were measured using a density-meter (Kyoto Electronics DA 300).

Raman spectra were deconvoluted to extract single Raman bands. A single Raman band is assumed to be represented as a pseudo-Voigt function, $f_{\mathrm{V}}(v)=\gamma f_{\mathrm{L}}(v)+(1-\gamma) f_{\mathrm{G}}(v)$, where $f_{\mathrm{L}}(v)$ and $f_{\mathrm{G}}(v)$ stand for the Lorentzian and Gaussian components, respectively, and the parameter $\gamma(0<\gamma<1)$ is the fraction of the Lorentzian component. To avoid any uncertainty in obtaining the $\gamma$ value of the peaks, the value was fixed to that obtained at the highest molarity alkaline metal ions. The intensity $I$ of a single Raman band is evaluated according to $I=\gamma I_{\mathrm{L}}+(1-\gamma) I_{\mathrm{G}}$, where $I_{\mathrm{L}}$ and $I_{\mathrm{G}}$ denote integrated intensities of the Lorentzian and Gaussian components, respectively. A nonlinear leastsquare curve-fitting program, based on the Marquardt-Levenberg algorithm, ${ }^{23,24}$ was developed in our laboratory and used throughout the analyses.

\section{MD simulations}

Lennard-Jones (LJ) and Coulomb terms were taken into account for intermolecular interactions. For the neat ionic liquid, the force field constructed by Lopes and Pádua et al. ${ }^{25}$ was employed, which means that all simulations reported in this work were based on the OPLS-AA ${ }^{26}$ convention. With regard to $\mathrm{Li}^{+}$, we used two kinds of intermolecular potential parameters, i.e., one was that proposed by Soetens et al. ${ }^{27}$ for the molecular simulations of carbonates solutions containing $\mathrm{Li}^{+}$, and the other was CFF force fields. ${ }^{28}$ In our simulations, Gear's predictorcorrector algorithm ${ }^{29}$ was employed for the integrals of the equation of motion. The system temperature and pressure were controlled by Nose's ${ }^{30}$ and Parrinello-Rahman's ${ }^{31}$ methods. The Coulombic long-range interactions were treated by Ewald's method with a cutoff distance of $11 \AA$.

As the first step in the simulations, NTP ensembles at $2000 \mathrm{~K}$ and $10000 \mathrm{~atm}$ were employed, with $38 \mathrm{Li}^{+}, 218 \mathrm{EMI}^{+}$and 256 TFSA- ions for the mole fraction of an $x=0.15$ solution (and also $82 \mathrm{Li}^{+}, 174 \mathrm{EMI}^{+}$and $256 \mathrm{TFSA}^{-}$for $x=0.32$ ) set at low density inside a cubic box with periodic boundary conditions. These ensembles were simulated until near-equilibrium conditions were achieved, a process that took a few hundred 


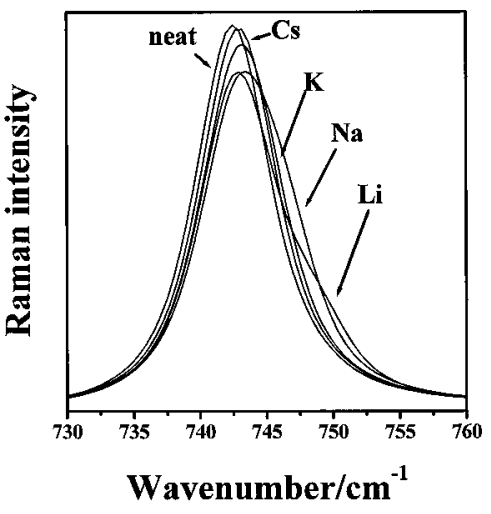

Fig. 1 Raman spectra in the frequency range of $730-760 \mathrm{~cm}^{-1}$ for [BMI][TFSA] ionic liquid solutions containing ca. $0.5 \mathrm{~mol} \mathrm{dm}^{-3}$ MTFSA (M = Li, Na, K and Cs), measured at $298 \mathrm{~K}$.

picoseconds. Then, the ensembles were changed to NTV, and the system volumes were fixed to the average values obtained from the previous NTP ensemble runs. These second-step equilibrations were typically calculated during 500 ps. The obtained trajectories were analyzed to check if the ions were fully mixed, and the final configurations were employed as the initial sets for the final NTP ensemble simulations at 1 atm and $298 \mathrm{~K}$. The final simulations typically consisted of a 1-ns equilibration period, followed by $1 \mathrm{~ns}$ production runs. The trajectories in the last 500 ps of the production runs were then analyzed.

The density values as ensemble averages were 1.614(6) and $1.663(6) \mathrm{g} \mathrm{cm}^{-3}$ for $x=0.15$ and 0.30 , respectively. The experimentally determined values were $1.55981(5) \mathrm{g} \mathrm{cm}^{-3}$ and $1.61235(3) \mathrm{g} \mathrm{cm}^{-3}$ at $298.15 \mathrm{~K}$ for the respective ionic liquid solution. The predicted densities agreed with the measured ones within $c a .3 \%$ accuracy in this work.

All simulations were carried out using Fujitsu Materials Explorer 4.0 on a Fujitsu PRIMEQUEST 580 at the Computing and Communications Center, Kyushu University.

\section{Results and Discussion}

\section{Solvation structure in $\mathrm{BMI}^{+} \mathrm{TFSA}^{-}$}

Raman spectra for [BMI][TFSA] ionic liquid solutions containing alkaline metal ions at the frequency range of 730 $760 \mathrm{~cm}^{-1}$ are shown in Fig. 1, and the dependence on the alkaline metal ion concentration is also shown in Fig. 2. In this frequency region, it is well established that the Raman band assigned to the $\mathrm{CF}_{3}$ bending vibration $\delta_{5}\left(\mathrm{CF}_{3}\right)$ coupled with the S-N stretching one $v_{\mathrm{s}}(\mathrm{SNS})$ of TFSA- appears at $743 \mathrm{~cm}^{-1} .^{32}$ The Raman band is accompanied by that of a higher frequency ascribable to the anion bound to the $\mathrm{Li}^{+}$ion, dissolving LiTFSA salt. ${ }^{14-16,20}$ In the frequency range, the Raman spectra for the ionic liquid containing $\mathrm{Li}^{+}$were similar to those previously reported for [EMI][TFSA], as expected. ${ }^{20}$ As can be seen in Fig. 2, with the $\mathrm{Na}^{+}$ion, a new Raman band ascribable to the anion bound to $\mathrm{Na}^{+}$ion is clearly found at the higher frequency side relative to that of the neat ionic liquid, like the $\mathrm{Li}^{+}$ion. Such a higher frequency shift has been found in Raman spectra for a polymer electrolyte system containing NaTFSA salt. ${ }^{33}$ On the other hand, with $\mathrm{K}^{+}$and $\mathrm{Cs}^{+}$ions of relatively large ionic radii, single Raman bands solely appeared with peak positions of slightly higher frequency. It should be noted that, strictly speaking, even the Raman band observed at $743 \mathrm{~cm}^{-1}$ for neat [BMI][TFSA] is also affected by the ion-ion interaction with the $\mathrm{BMI}^{+}$cation in

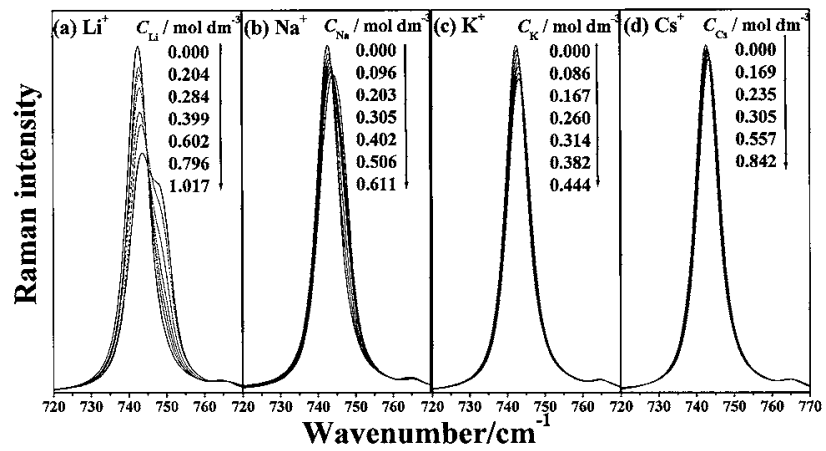

Fig. 2 Raman spectra of [BMI][TFSA] ionic liquid solutions containing MTFSA $(\mathrm{M}=\mathrm{Li}, \mathrm{Na}, \mathrm{K}$ and $\mathrm{Cs})$ at $298 \mathrm{~K}$ with varying MTFSA concentration.

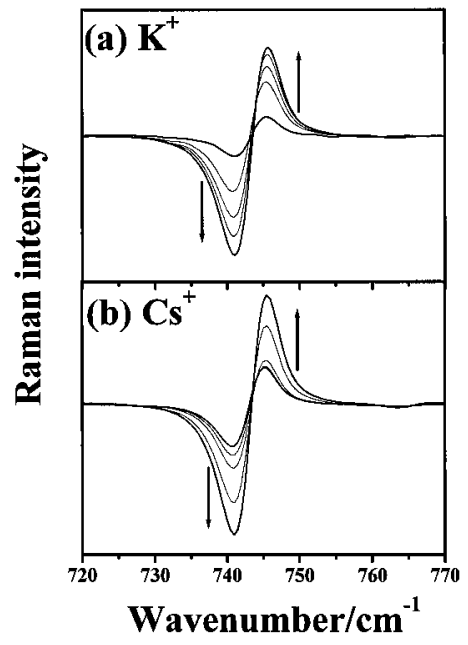

Fig. 3 Difference Raman spectra of [BMI][TFSA] ionic liquid solutions containing KTFSA (a) and CsTFSA (b) salts, respectively.

ionic liquids. The higher frequency shifts found in Raman bands for ionic liquids containing $\mathrm{K}^{+}$and $\mathrm{Cs}^{+}$ions may be due to the superposition of those for TFSA- ions bound to the metal ions and bulk one. Thus, Raman difference spectra for ionic liquids containing $\mathrm{K}^{+}$and $\mathrm{Cs}^{+}$ions were evaluated by subtracting the Raman spectrum for the neat ionic liquid (Fig. 3). As clearly shown in Fig. 3, asymmetric Raman difference spectra, like differential ones, with the obvious iso-scattering points of $c a$. 744 and $743 \mathrm{~cm}^{-1}$ for $\mathrm{K}^{+}$and $\mathrm{Cs}^{+}$solution, respectively, were obtained, indicating that the Raman bands ascribable to the anions bound to $\mathrm{K}^{+}$and $\mathrm{Cs}^{+}$ions are seriously overlapped with that arising from the bulk anion, and observed as single Raman bands, because the higher frequency shifts are quite small. This is plausible by taking into account the small charge density of singly charged $\mathrm{K}^{+}$and $\mathrm{Cs}^{+}$ions of relatively large ionic radii. This will be discussed in a later section more quantitatively.

As can be seen in Fig. 2, with $\mathrm{Li}^{+}$and $\mathrm{Na}^{+}$ions, the Raman bands from the bulk TFSA ${ }^{-}$evidently decreased in intensity with increasing the metal ion concentration. On the other hand, the minimum of the negative value found in the Raman difference spectra for ionic liquids including $\mathrm{K}^{+}$and $\mathrm{Cs}^{+}$ions (Fig. 3) decreased in intensity (the negative peak height becomes lower more negatively) with practically unchanged peak positions, which indicates that the intensity of the Raman bands for the bulk TFSA $^{-}$in the ionic liquid solutions decreased as the 


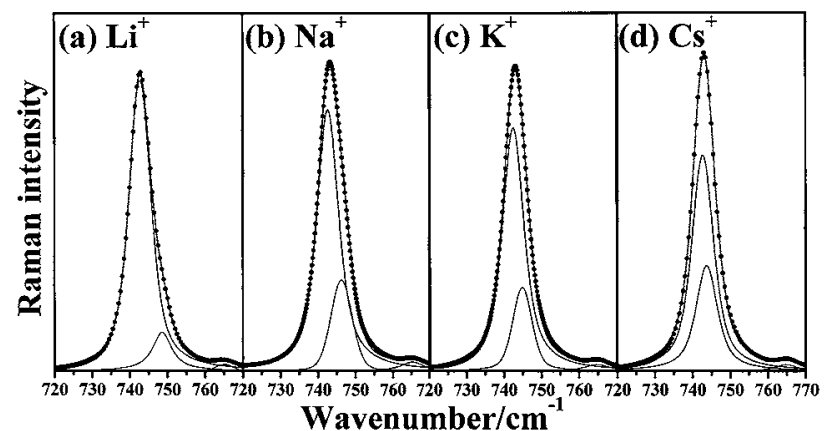

Fig. 4 Typical extracted single Raman bands in the frequency range of $720-770 \mathrm{~cm}^{-1}$ for [BMI][TFSA] ionic liquid solutions for $c a .0 .5$ mol $\mathrm{dm}^{-3}$ MTFSA ( $\mathrm{M}=\mathrm{Li}, \mathrm{Na}, \mathrm{K}$ and $\mathrm{Cs}$ ), measured at $298 \mathrm{~K}$.

increase of the concentration of $\mathrm{K}^{+}$and $\mathrm{Cs}^{+}$ions, like $\mathrm{Li}^{+}$and $\mathrm{Na}^{+}$ions. As previously reported ${ }^{20}$ a quantitative analysis of the decrease in the integral intensity of the Raman band for bulk TFSA $^{-}$can yield the solvation numbers for the dissolved metal ion, when a two-state approximation, one in bulk and the other bound to the metal ion, can be reasonably held. As discussed above, we assumed that the two-state approximation could hold adequately, even in the case of $\mathrm{K}^{+}$and $\mathrm{Cs}^{+}$ions. Thus, we attempted to extract single Raman bands from the observed Raman spectra to yield the integral intensity of the Raman band for bulk TFSA ${ }^{-}$. During the course of analysis, we employed some transcendental criteria, i.e., the peak position and the molar Raman scattering coefficient for bulk TFSA ${ }^{-}$in the respective solution should be independent from the dissolving metal ions, and the band shape should remain practically unchanged. Typical results for Raman band deconvolution of the nonlinear least squares are shown in Fig. 4. As can be seen from this figure, the Raman band intensity for the bulk TFSA- in the ionic liquid solutions containing almost the same concentration of $c a$. $0.5 \mathrm{~mol} \mathrm{dm}{ }^{-3}$ alkaline metal ions obviously decreases in the order of $\mathrm{Li}^{+}>\mathrm{Na}^{+} \approx \mathrm{K}^{+}>\mathrm{Cs}^{+}$, implying that the solvation numbers for the alkaline metal ions increases with the ionic radii. Thus, a more quantitative analysis was carried out while varying the alkaline metal salts concentration.

The integral intensity $I_{\mathrm{f}}$ of an extracted single Raman band of the bulk TFSA ${ }^{-}$anion can be represented as $I_{\mathrm{f}}=J_{\mathrm{f}} c_{\mathrm{f}}$, where $J_{\mathrm{f}}$ and $c_{\mathrm{f}}$ stand for the molar Raman scattering coefficient and the molarity of the TFSA ${ }^{-}$anion in the bulk, respectively. $c_{\mathrm{f}}$ is given as $c_{\mathrm{f}}=c_{\mathrm{T}}-c_{\mathrm{b}}=c_{\mathrm{T}}-n c_{\mathrm{Li}}$, where $c_{\mathrm{T}}, c_{\mathrm{b}}, c_{\mathrm{M}}$ and $n$ denote the molarities of the total and bound TFSA ${ }^{-}$anions, and the molarity and the solvation number of the alkaline metal ions, respectively. Taking into consideration the above two relationships, we obtained the following relationship: $I_{\mathrm{f}} / c_{\mathrm{M}}=J_{\mathrm{f}}(R-n)$, where $R=$ $c_{\mathrm{T}} / c_{\mathrm{M}}$. A plot of $I_{\mathrm{f}} / c_{\mathrm{Li}}$ against $R$ thus yields a straight line, and the $n$ value is obtained as $n=-\beta / \alpha$ from a slope of $\alpha=J_{\mathrm{f}}$ and an intercept of $\beta=-J_{\mathrm{f}} n . I_{\mathrm{f}} / c_{\mathrm{M}} v s . R$ plots for the respective alkaline metal ion are shown in Fig. 5. As can be seen from this figure, plots for all of the alkaline metal ions examined here fall on straight lines, which suggests that the solvation numbers for the alkaline metal ions hardly depend on the concentration examined here. In addition, almost the same slope for the respective alkaline metal ion (the slope yields the Raman scattering coefficient for the bulk TFSA ${ }^{-}$), indicating that Raman band deconvolution was made adequately throughout this work, and thus the obtained solvation numbers could be reliable. The evaluated values for the solvation numbers for the alkaline metal ions are listed in Table 1, accompanied by the Raman spectroscopic parameters. The values of the solvation numbers

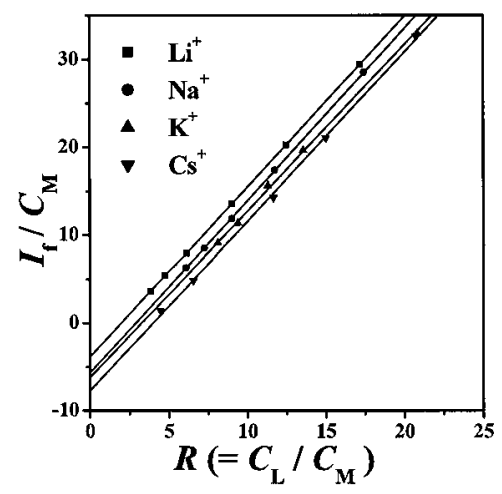

Fig. 5 Plots of $I_{\mathrm{f}} / c_{\mathrm{M}} v s$. R. Solvation numbers of alkaline metal ions in ionic liquid were evaluated from the slope and the intercept for linear least squares (see text).

Table 1 Solvation numbers $n$ in [BMI][TFSA] ionic liquids at $298 \mathrm{~K}$, Shannon's ionic radii $\mathrm{r} / \mathrm{pm}$ for alkaline metal ions and Raman spectroscopic parameters such as $\Delta v / \mathrm{cm}^{-1}$, Raman scattering coefficients $J_{\mathrm{f}}$ and $J_{\mathrm{b}}$, and the ratio $J_{\mathrm{b}} / J_{\mathrm{f}}$

\begin{tabular}{llrllll}
\hline & \multicolumn{1}{c}{$n$} & $r$ & $\Delta v$ & \multicolumn{1}{c}{$J_{\mathrm{f}}$} & $J_{\mathrm{b}}$ & $J_{\mathrm{b}} / J_{\mathrm{f}}$ \\
\hline $\mathrm{Li}^{+}$ & $1.95(3)$ & 59 & 5.9 & $1.930(6)$ & 1.3 & $0.68(6)$ \\
$\mathrm{Na}^{+}$ & $2.88(2)$ & 102 & 3.4 & $1.952(2)$ & 1.6 & $0.86(2)$ \\
$\mathrm{K}^{+}$ & $3.2(1)$ & 138 & 2.1 & $1.89(1)$ & 1.4 & $0.82(9)$ \\
$\mathrm{Cs}^{+}$ & $3.9(2)$ & 174 & 1.6 & $1.92(3)$ & 1.4 & $0.77(6)$ \\
\hline
\end{tabular}

are 1.95 for lithium ion, 2.88 for sodium ion, 3.2 for potassium ion and 3.9 for cesium ion, respectively. Taking into consideration the experimental errors, the numbers of solvated TFSA ${ }^{-}$anions could be 2 for $\mathrm{Li}^{+}, 3$ for $\mathrm{Na}^{+}$and $\mathrm{K}^{+}$, and 4 for $\mathrm{Cs}^{+}$, respectively. Moreover, it is plausible that, in the liquid state, the $\mathrm{TFSA}^{-}$anion predominantly acts as a bidentate ligand with one oxygen atom in each $\mathrm{SO}_{2}$ group. Consequently, it is plausible that the atomic coordination numbers for $\mathrm{Li}^{+}, \mathrm{Na}^{+}, \mathrm{K}^{+}$ and $\mathrm{Cs}^{+}$are 4, 6, 6 and 8, respectively, in the ionic liquid.

It is worth comparing with the coordination numbers or the solvation structures of the alkaline metal ions in conventional molecular liquids. With regard to lithium ion, the hydration structure revealed by various techniques was recently reviewed. ${ }^{34}$ The hydration numbers of $\mathrm{Li}^{+}$ion distribute from 4 to 6 , depending on the counter anion and the concentrations of the salts. However, we recently demonstrated that lithium ion predominantly exists as a 4-coordinated structure in propylene carbonate solutions by neutron diffraction with the ${ }^{6 / 7} \mathrm{Li}$ isotope substitution technique. ${ }^{35}$ According to previously reported neutron scattering studies, 4-coordinated structures of $\mathrm{Li}^{+}$ion would be favorable species in aqueous solutions ${ }^{36}$ and in nonaqueous solutions. ${ }^{37}$ Compared with the solvation structures in conventional molecular solvent solutions, the similar 4coordinated structure of $\mathrm{Li}^{+}$ion in ionic liquids seems to be reasonable. With the $\mathrm{Na}^{+}$ion, the hydration numbers seem to depend on the salt concentration, i.e., 6 and 4 in dilute and concentrated solution, respectively. ${ }^{38}$ On the other hand, experimental investigations on the $\mathrm{Na}^{+}$ion solvation structure in non-aqueous solution are scarce. ${ }^{39}$ With $\mathrm{K}^{+}$and $\mathrm{Cs}^{+}$, recent experimental and theoretical studies on the hydration structures can be found in the literature, ${ }^{40}$ while, as far as we aware, there is no published experimental work on the solvation structures in non-aqueous solvents. We believe that the solvation structures of $\mathrm{Na}^{+}, \mathrm{K}^{+}$and $\mathrm{Cs}^{+}$ions in non-aqueous solvents are not clear at 
the present stage.

To the best of our knowledge, no neutron/X-ray scattering experiments for the alkaline metal ions solvation in the ionic liquid has been reported until the present, while a few theoretical studies were published. Borodin et al. investigated the lithium ion solvation structure and transport property in $\mathrm{N}$-alkyl- $\mathrm{N}$ methylpyrrolidinium bis(trifluoromethanesulfonyl)amide by MD simulations based on a many-body polarizable model. ${ }^{41}$ According to their simulations, the $\mathrm{Li}^{+}$ion is coordinated by 4 oxygen atoms, and $65 \%$ of the $\mathrm{Li}^{+}$ions exist as the oligomer, in which two $\mathrm{Li}^{+}$ions are bridged by three TFSA- ions in a bidentate manner, i.e., two oxygen atoms in a $\mathrm{SO}_{2}$ group coordinate to $\mathrm{Li}^{+}$ion. Such a solvation structure agrees with the LiTFSA crystal structure, ${ }^{42}$ while differing from that of $\mathrm{Li}_{2}[$ EMI $][\mathrm{TFSA}]_{3}{ }^{43}$ On the other hand, according to MD simulations based on the effective pair potentials, ${ }^{44}$ three TFSA ions solvate to a $\mathrm{Li}^{+}$ion, which is surrounded by five oxygen atoms, i.e., two of bidentate $\mathrm{TFSA}^{-}$and one mono-dentate. In addition, the $\mathrm{Li}^{+}$ion solvation structure depends on its concentration, i.e., with an increase of the $\mathrm{Li}^{+}$ion concentration, the average number of solvated TFSA ${ }^{-}$increases, whilst the average number of donating oxygen atoms decreases. Sieffert and Wipff have so far studied alkaline metal ions of $\mathrm{Na}^{+} \mathrm{K}^{+}, \mathrm{Rb}^{+}$ and $\mathrm{Cs}^{+}$by quantum chemical calculations and MD simulations in connection with solvent extraction and/or a liquid-liquid interface. ${ }^{45}$ They evaluated the interaction energy for the aggregates $\left[\mathrm{Na}^{+}\left(\mathrm{TFSA}^{-}\right)_{\mathrm{n}}\right](n=1-3)$ in the gas phase by quantum chemical calculations, and found that the interaction energy shows a minimum at $n=2$. In addition, in their simulations, $\mathrm{Na}^{+}$is surrounded by $4.0 \mathrm{TFSA}^{-}$via $\mathrm{O}$ atoms of 5.7, corresponding to two bidentate and two mono-dentate TFSA- ions. $\mathrm{Cs}^{+}$is coordinated by $5 \mathrm{TFSA}^{-}$anions via 6.2 oxygen atoms on the average, one anion being bidentate and the others being mono-dentate. Thus, it would be necessary to make more experimental and theoretical efforts to draw more accurate pictures of alkaline metal ion solvation at a molecular level.

Ion-ion interaction between alkaline metal ion and TFSA- ion

It is difficult to obtain information on the M-O bond length in solvated alkaline metal ions in solution by Raman spectroscopy directly. Nevertheless, though rough, information related to the bond length can be obtained from careful insight into the Raman spectra, if we take into account the well-accepted relationship between the coordination number and the bond length, i.e., the larger is the coordination number, the longer is the bond length. As indicated above, the solvation numbers (and thus the atomic coordination number) of the alkaline metal ions were evaluated, so that we could know the ionic radii of the solvated alkaline metal ions in ionic liquids. According to Shannon, ${ }^{46}$ the ionic radii are 59, 102, 138 and $174 \mathrm{pm}$ for $\mathrm{Li}^{+}, \mathrm{Na}^{+}, \mathrm{K}^{+}$and $\mathrm{Cs}^{+}$of the 4-, 6-, 6- and 8-coordinated structure, respectively. By using these values, the relationship between $\Delta v$ and the ionic radii $r$ of the solvated alkaline metal ions in the ionic liquid can be directly discussed. As the ionic radius of the alkaline metal ion is smaller, the higher frequency shift of the Raman band arising from the anions bound to the metal ions is larger. In other words, $\Delta v$ may be proportional to the $n$th power of the reciprocal ionic radii $r$. Thus, assuming that the relationship $\Delta v=(a r)^{-\mathrm{n}}$ can hold, where $a$ represents parameters for the effective ionic radii of the metal ions, plots of $\log \left(\Delta v / \mathrm{cm}^{-1}\right) v s . \log (r / \mathrm{pm})$ yield the value of $n$ as their slope. Furthermore, if the ion-ion interactions between the alkaline metal ions and the anion are electrostatic, it is expected that a value close to unity, because $\Delta v$ is proportional to the reciprocal $r$. As shown in Fig. 6, the plot falls on a straight line, suggesting that the TFSA $^{-}$non

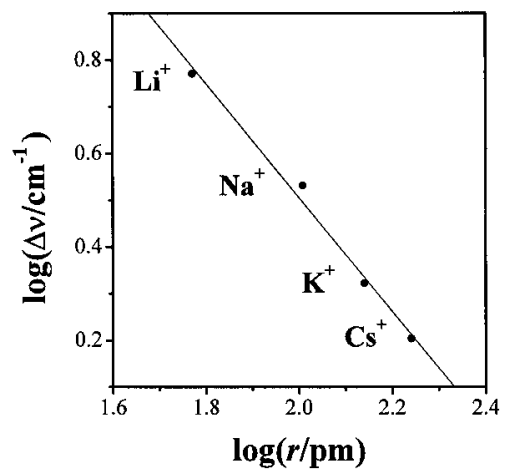

Fig. 6 Plots of $\log \left(\Delta v / \mathrm{cm}^{-1}\right) v s . \log (r / \mathrm{pm}) ; n$ was evaluated from the slope for linear least squares, according to the relationship $\Delta v=(a r)^{\mathrm{n}}$.

coordinates to all alkaline metal ions examined here with practically the same binding mode, i.e., the bidentate one via one oxygen atom from each $\mathrm{SO}_{2}$ group. Moreover, the value of the slope was evaluated to be 0.999(5). Therefore, it can be deduced that the ion-ion interactions between the alkaline metal ions and TFSA ${ }^{-}$ion are essentially electrostatic, as expected.

In addition, we could discuss the ion-ion interaction between the alkaline metal ions and TFSA- in terms of the Raman scattering coefficient. When the alkaline metal ions are coordinated by $\mathrm{TFSA}^{-}$via oxygen atoms, the $\mathrm{S}-\mathrm{O}$ bond, and probably also the C-F bond, should be polarized. The Raman scattering coefficient (scattering cross section) is proportional to the polarizability, and it is thus expected that the Raman scattering coefficient of the vibration mode including the motions of the S-O group would vary from the value for the bulk TFSA ${ }^{-}$, when coordinating to the alkaline metal ions. The relationship $I_{\mathrm{b}}=J_{\mathrm{b}} c_{\mathrm{b}}=J_{\mathrm{b}} n c_{\mathrm{Li}}$ also holds for the TFSA ${ }^{-}$anion bound to the metal ion, and the molar Raman scattering coefficient $J_{\mathrm{b}}$ is obtained from the $I_{\mathrm{b}} v s$. $c_{\mathrm{M}}$ plot for the Raman bands arising from the bound anion. In fact, the $J_{\mathrm{b}} / J_{\mathrm{f}}$ values for all of the alkaline metal ions examined here are smaller than unity, as shown in Table 1. Moreover, though large uncertainties exist, the smallest value was obtained for the $\mathrm{Li}^{+}$ion of the smallest ionic radius, as expected. However, ab initio calculations of high levels sufficient to predict correct polarizability are necessary to discuss more quantitatively.

\section{Conformation of TFSA- in the first solvation sphere of alkaline metal ion}

Figure 7 displays Raman spectra for ionic liquids containing alkaline metal ions of $c a .0 .5 \mathrm{~mol} \mathrm{dm}^{-3}$ in the frequency range of $370-450 \mathrm{~cm}^{-1}$, where a specific Raman band arising from cis TFSA $^{-}\left(407 \mathrm{~cm}^{-1}\right)$ and those from trans TFSA ${ }^{-}$(398 and 413 $\mathrm{cm}^{-1}$ ) can be observed for the neat ionic liquid. ${ }^{19}$ As previously reported, ${ }^{20}$ when dissolving the $\mathrm{Li}^{+}$ion, the $407 \mathrm{~cm}^{-1}$ band increases relative to the other two Raman bands from trans TFSA $^{-}$anion. The same can be observed in this work. Moreover, as can be seen in Fig. 7, similar enhanced Raman bands of $407 \mathrm{~cm}^{-1}$ were evidently found in the Raman spectra for ionic liquids containing $\mathrm{Na}^{+}$and $\mathrm{K}^{+}$ions. On the other hand, such an increase of the $407 \mathrm{~cm}^{-1}$ Raman band in intensity could not be observed for ionic liquid containing $\mathrm{Cs}^{+}$. This observation strongly suggests that the TFSA- ion prefers the cis conformation, when it coordinates to alkaline metal ions of relatively small ionic radii. It should be noted that, in a neat ionic liquid, trans TFSA- is a more favorable isomer relative to cis one, as shown both experimentally ${ }^{19,47}$ and theoretically. ${ }^{48}$ 


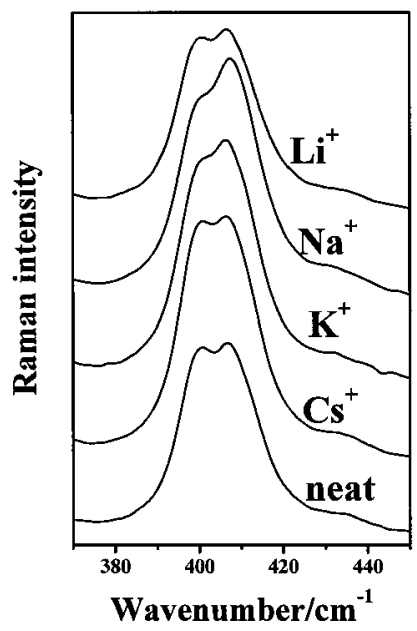

Fig. 7 Raman spectra in the frequency range of $360-450 \mathrm{~cm}^{-1}$ for [BMI][TFSA] ionic liquid solutions $c a .0 .5 \mathrm{~mol} \mathrm{dm}^{-3}$ MTFSA ( $\mathrm{M}=$ $\mathrm{Li}, \mathrm{Na}, \mathrm{K}$ and $\mathrm{Cs}$ ), measured at $298 \mathrm{~K}$.

The more stabilized cis TFSA- bound to metal ions relative to the trans one can also be found in crystals. According to our survey of the Cambridge Structure Database (CSD), ${ }^{49} 137$ molecular structures of the TFSA- ion in crystals have been reported except the disordered ones, in which there are 81 and 56 anions bound to metal ions and non-metal cations, respectively. With the former, the C-S...S-C dihedral angle distribution corresponding to the anions bound to metal ions are rather different from those interacting with non-metal ions, as shown in Fig. 8.

This is also supported by quantum mechanical calculations. With regard to the $\mathrm{Li}^{+}$ion, the binding energy for $[\mathrm{Li}$ (cis TFSA $\left.)_{2}\right]$ is slightly larger than that for [Li(trans TFSA $\left.)_{2}\right]$ in the gas phase, as previously shown by our DFT calculations at the B3LYP/6-311+G(d,p) level of theory. ${ }^{20}$ On the other hand, according to DFT calculations at the B3LYP/6-31G(d) level of theory by Sieffert and Wipff, ${ }^{45 a}$ the binding energy for $[\mathrm{Na}$ (cis TFSA $\left.)_{2}\right]$ is smaller than that for $\left[\mathrm{Na}(\text { trans TFSA })_{2}\right]$. From these calculations, it can be deduced that cis TFSA $^{-}$is stabilized relative to trans TFSA-, when it coordinates to the $\mathrm{Li}^{+}$ion of small ionic radius, however, there is no such stabilization when it binds to the larger $\mathrm{Na}^{+}$ion.

In order to shed more light on the conformation of a TFSA anion bound to alkaline metal ions, we performed MD simulations for [EMI][TFSA] ionic liquids containing the $\mathrm{Li}^{+}$ ion. We adopted two different $\mathrm{Li}^{+}-\mathrm{O}$ intermolecular potentials, as described above. The solvation structures of the $\mathrm{Li}^{+}$ion in our simulations will be described elsewhere, compared with other experimental evidences. Here, we focus only on the conformational isomerism of TFSA ${ }^{-}$. For a discussion of the conformational isomerism of $\mathrm{TFSA}^{-}$, it is useful to extract the dihedral angle distributions with respect to the pseudo-dihedral angle of the CS...SC $\phi$ in the anion, i.e., $\phi \approx 40^{\circ}$ and $170^{\circ}$ represent cis- and trans TFSA $^{-}$, respectively. ${ }^{25,48}$ Figure 9 shows the CS...SC dihedral angle distributions derived from MD simulations for the respective force field with varying LiTFSA salt mole fractions in ionic liquid solutions. As can be seen, it is evidently found that trans TFSA- (peak at $c a .165^{\circ}$ ) decreased, and oppositely the $c i s$ isomer (peak at $c a .30^{\circ}$ ) increased with an increase of the LiTFSA mole fractions. Moreover, the conformational behavior of increasing LiTFSA mole fraction is independent from the two kinds of $\mathrm{Li}^{+}-\mathrm{O}$ intermolecular

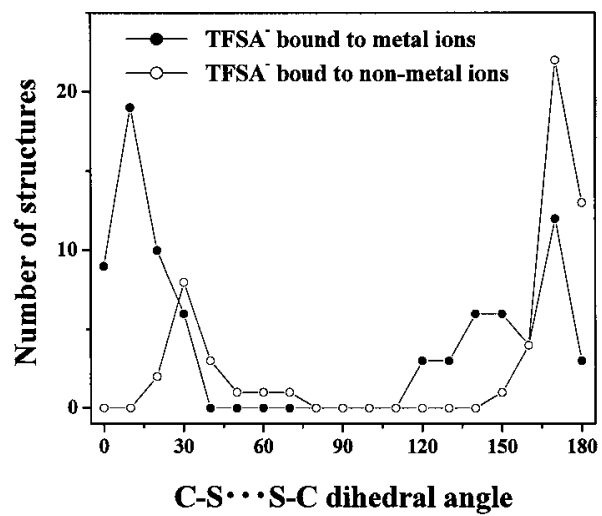

Fig. 8 CS -..SC dihedral angle distribution for TFSA ${ }^{-}$bound to metal ions $(\bullet)$ and non-metal ions $(O)$ in crystals found in the CSD database.

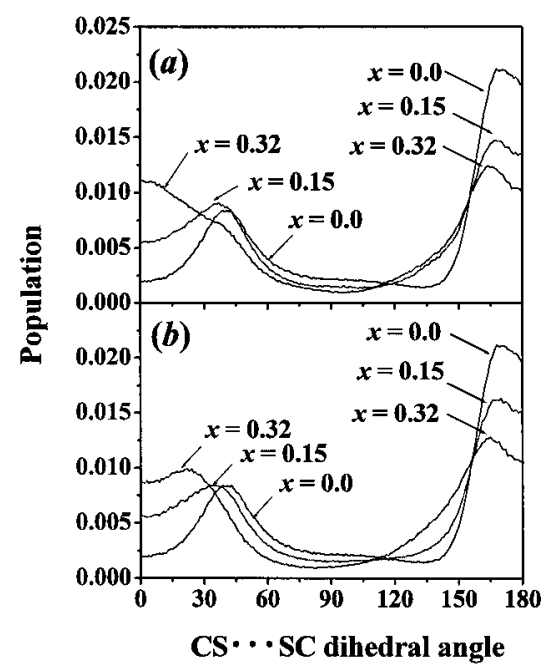

Fig. 9 CS…SC dihedral angle distribution of TFSA- derived from MD simulations for [BMI][TFSA] ionic liquid containing LiTFSA. $x$ stands for the mole fraction of LiTFSA in $\left[\mathrm{Li}_{x} \mathrm{BMI}_{(1-\mathrm{x})} \mathrm{TFSA}\right]$. Employed inter-molecular potential for $\mathrm{Li}^{+}-\mathrm{O}\left(\mathrm{TFSA}^{-}\right)$was that proposed by Sohtens et al. (a) and CFF force fields (b), respectively.

potentials employed in this study. It should be noted that our simulations are classic ones and are based on the effective pair potentials of simple LJ and Coulombic interactions. The preferred conformation of cis isomer around the $\mathrm{Li}^{+}$ion of small ionic radius could be attributable to a larger dipole moment for the isomer relative to the other. ${ }^{19,20}$ In fact, similar preferred conformational isomerism in the first coordination sphere of the $\mathrm{Li}^{+}$ion was found in non-aqueous solvent solutions of dimethyl carbonate. ${ }^{27}$ Though we have no thermodynamic data for ion solvation in ionic liquids, such a preferred conformational isomerism may stabilize the central metal ion of small ionic radius relative to a larger one, as was previously shown by our systematic studies on the ion solvation in non-aqueous solvent solutions of amides. ${ }^{50}$

\section{Conclusion}

Raman spectra for 1-butyl-3-methylimidazolium bis(trifluoromethanesulfonyl)amide containing alkaline metal salts of TFSA ${ }^{-}$, MTFSA ( $\mathrm{M}=\mathrm{Li}, \mathrm{Na}, \mathrm{K}$ and $\mathrm{Cs}$ ), were recorded in the frequency 
range of $200-1800 \mathrm{~cm}^{-1}$, with varying salt concentration at 298 K. Quantitative analyses of Raman spectra with sufficient care yielded the solvation numbers to be 1.95 for $\mathrm{Li}^{+}, 2.88$ for $\mathrm{Na}^{+}$, 3.2 for $\mathrm{K}^{+}$and 3.9 for $\mathrm{Cs}^{+}$, respectively. 4-, 6-, 6- and 8coordinated structures for $\mathrm{Li}^{+}, \mathrm{Na}^{+} \mathrm{K}^{+}$and $\mathrm{Cs}^{+}$, respectively, in an ionic liquid were proposed based on the thus-evaluated solvation numbers and the bidentate binding mode of TFSA ${ }^{-}$. Relative Raman shifts for the bound $\mathrm{TFSA}^{-}$to that for the bulk one show a good linear correlation with the reciprocal ionic radii for the solvated alkaline metal ions, according to Shannon's ionic radii corresponding to the atomic coordination numbers proposed here.

From the Raman spectra in the frequency range of $370-450$ $\mathrm{cm}^{-1}$, the conformation of TFSA- in the first solvation sphere of the alkaline metal ions were discussed. Experimental evidence for the preferred conformational isomerism of cis TFSA- bound to $\mathrm{Li}^{+}$and $\mathrm{Na}^{+}$ions of the relatively small ionic radii was provided, and well supported by DFT calculations and MD simulations. The preferred conformational isomerization of cis TFSA- bound to small alkaline metal ions was ascribed to its larger dipole moment relative to trans TFSA $^{-}$.

\section{Acknowledgements}

This work has been financially supported by Grant-in-Aids for Scientific Research No. 19003963, 19350033, 19750062 and 20350037, and by a Grant-in-Aid for the Global COE Program, "Science for Future Molecular Systems" from the Ministry of Education, Culture, Sports, Science and Technology.

\section{References}

1. H. Ohno (ed.), "Electrochemical Aspects of Ionic Liquids", 2005, John \& Wiley Sons, Inc., Hoboken, NJ.

2. (a) M. Yoshizawa, W. Xu, and C. A. Angell, J. Am. Chem. Soc., 2003, 125, 15411. (b) W. Xu and C. A. Angell, Science, 2003, 302, 422. (c) M. A. B. H. Susan, A. Noda, S. Mitsushima, and M. Watanabe, Chem. Commun., 2003, 938.

3. (a) H. Sakaebe and H. Matsumoto, Electrochem. Commun., 2003, 5, 594. (b) H. Nakagawa, S. Izuchi, K. Kuwana, T. Nukuda, and Y. Aihara, J. Electrochem. Soc., 2003, 150, A695. (c) S. Seki, Y. Kobayashi, H. Miyashiro, Y. Ohno, A Usami, Y. Mita, N. Kihira, M. Watanabe, and N. Terada, $J$. Phys. Chem. B, 2006, 110, 10228.

4. (a) A. B. McEwen, H. L. Ngo, K. LeComte, and J. L. Goldman, J. Electrochem. Soc., 1999, 146, 1687. (b) M. Ue, M. Takeda, A. Toriumi, A. Kominato, R. Hagiwara, and Y. Ito, J. Electrochem. Soc., 2003, 150, A499.

5. (a) P. Wang, S. M. Zakeeruddin, P. Comte, I. Exnar, and M. Gratzel, J. Am. Chem. Soc., 2003, 125, 1166. (b) P. Wang, S. M. Zakeeruddin, J. E. Moser, M. K. Nazeeruddin, T. Sekiguchi, and M. Gratzel, Nat. Mater, 2003, 2, 402. (c) N. Yamanaka, R. Kawano, W. Kubo, N. Masaki, T. Kitamura, Y. Wada, M. Watanabe, and S. Yanagida, J. Phys. Chem. B, 2007, 111, 4763.

6. (a) M. L. Dietz, Sep. Sci. Technol., 2006, 41, 2047. (b) F. Kubota and M. Goto, Solvent Extr. Res. Dev., Jpn., 2006, 13, 23. (c) M. L. Dietz, J. A. Dzielawa, M. P. Jensen, J. V. Beitz, and M. Borkowski, ACS Symp. Ser. 902, Ionic Liquids IIIB: Fundamentals, Progress, Challenges, and Opportunities, 2005, 2.

7. T. Tsukatani, H. Katano, H. Tatsumi, M. Deguchi, and N.
Hirayama, Anal. Sci., 2006, 22, 199.

8. (a) T. Kakiuchi, Anal. Chem., 2007, 79, 6442. (b) N. Nishi, H. Murakami, S. Imakura, and T. Kakiuchi, Anal. Chem., 2006, 78, 5805. (c) N. Tsujioka, S. Imakura, N. Nishi, and T. Kakiuchi, Anal. Sci., 2006, 22, 667.

9. C. Hardacre, Annu. Rev. Mater. Res., 2005, 35, 29.

10. K. Matsumoto and R. Hagiwara, J. Fluorine Chem., 2007, $128,317$.

11. (a) M. P. Jensen, J. A. Dzielawa, P. Rickert, and M. L. Dietz, J. Am. Chem. Soc., 2002, 124, 10664. (b) M. P. Jensen, J. Neuefeind, J. V. Beitz, S. Skanthakumar, and L. Soderholm, J. Am. Chem. Soc., 2003, 125, 15466.

12. C. Gaillard, I. Billard, A. Chaumont, S. Mekki, A. Ouadi, M. A. Denecke, G. Moutiers, and G. Wipff, Inorg. Chem., 2005, 44, 8355 .

13. (a) H. Ohtaki and T. Radnai, Chem. Rev., 1993, 93, 1157. (b) H. Ohtaki, Monatsh. Chem., 2001, 132, 1237.

14. M. Castriota, T. Caruso, R. G. Agostino, E. Cazzanelli, W. A. Henderson, and S. Passerini, J. Phys. Chem. A, 2005, 109, 92 .

15. J.-C. Lassègues, J. Grondin, and D. Talaga, Phys. Chem. Chem. Phys., 2006, 8, 5629.

16. L. J. Hardwick, M. Holzapfel, A. Wokaun, and P. Novák, J. Raman Spectrosc., 2007, 38, 110.

17. Y. Umebayashi, T. Fujimori, T. Sukizaki, M. Asada, K. Fujii, R. Kanzaki, and S. Ishiguro, J. Phys. Chem. A, 2005, 109, 8976.

18. T. Fujimori, K. Fujii, R. Kanzaki, K. Chiba, H. Yamamoto, Y. Umebayashi, and S. Ishiguro, J. Mol. Liq., 2007, 131 $132,216$.

19. K. Fujii, T. Fujimori, T. Takamuku, R. Kanzaki, Y. Umebayashi, and S. Ishiguro, J. Phys. Chem. B, 2006, 110, 8179.

20. Y. Umebayashi, T. Mitsugi, S. Fukuda, T. Fujimori, K. Fujii, R. Kanzaki, M. Takeuchi, and S. Ishiguro, J. Phys. Chem. B, 2007, 111, 13028

21. P. Nockemann, K. Binnemans, and K. Driesen, Chem. Phys. Lett., 2005, 415, 131.

22. R. W. Berg, M. Deetlefs, K. R. Seddon, I. Shim, and J. M. Thompson, J. Phys. Chem. B, 2005, 109, 19018.

23. D. W. Marquardt, J. Soc. Ind. Appl. Math., 1963, 11, 431.

24. W. H. Press, B. P. Flannery, S. A. Teukolsky, and W. T. Vetterling, "Numerical Recipes", 1989, Cambridge University Press.

25. (a) J. N. C. Lopes, J. Deschamps, and A. A. H. Pádua, J. Phys. Chem. B, 2004, 108, 2038. (b) J. N. C. Lopes and A. A. H. Pádua, J. Phys. Chem. B, 2004, 108, 16893.

26. W. L. Jorgensen, D. S. Maxwell, and J. Tirado-Rives, J. Am. Chem. Soc., 1996, 118, 11225.

27. J.-C. Soetens, C. Millot, and B. Maigret, J. Phys. Chem. A, 1998, 102, 1055 .

28. Z. Peng, C. S. Ewig, M.-J. Hwang, M. Waldman, and A. T. Hagler, J. Phys. Chem. A, 1997, 101, 7243.

29. (a) G. W. Gear, "Numerical Initial Value Problems in Ordinary Differential Equations", 1971, Prentice-Hall, Inc. (b) H. J. C. Berendsen and V. W. F. an Gunsteren, Proceeding of the Enrico Fermi Summer School on Molecular Dynamics Simulation of Statistical Mechanical System, G. Ciccotti and G. Hover, 1986, North Holland, 43.

30. (a) S. Nose, Mol. Phys., 1984, 52, 255. (b) S. Nose, J. Chem. Phys., 1984, 81, 511.

31. (a) M. Parrinello and A. Rahman, J. Appl. Phys., 1981, 52, 7182. (b) M. Parrinello and A. Rahman, Phys. Rev. Lett., 1980, 45, 1196.

32. (a) I. Rey, P. Johansson, J. Lindgren, J. C. Lassègues, J. 
Grondin, and L. Servant, J. Phys. Chem. A, 1998, 102, 3249. (b) W. Huang, R. Frech, and R. A. Wheeler, J. Phys. Chem., 1994, 98, 100. (c) A. Bakker, S. Gejji, J. Lindgren, K. Hermansson, and M. M. Probst, Polymer, 1995, 36, 4371.

33. A. Ferry, M. M. Doeff, and L. C. De Jonghe, J. Electrochem. Soc., 1998, 145, 998.

34. P. R. Smirnov and V. N. Trostin, Russ. J. Gen. Chem., 2006, $76,175$.

35. Y. Kameda, Y. Umebayashi, M. Takeuchi, M. A. Wahab, S. Fukuda, S. Ishiguro, M. Sasaki, Y. Amo, and T. Usuki, $J$. Phys. Chem. B, 2007, 111, 6104.

36. a) Y. Kameda, M. Sasaki, Y. Amo, and T. Usuki, Bull. Chem. Soc. Jpn., 2006, 79, 228. b) Y. Kameda, K. Mochiduki, M. Imano, H. Naganuma, M. Sasaki, Y. Amo, and T. Usuki, J. Mol. Liq., 2005, 119, 159. c) Y. Kameda, M. Imano, M. Takeuchi, S. Suzuki, T. Usuki, and O. Uemura, J. Non-Cryst. Solids, 2001, 293 - 295, 600. d) Y. Kameda, H. Ebata, and O. Uemura, Bull. Chem. Soc. Jpn., 1994, 67, 929. e) Y. Kameda and O. Uemura, Bull. Chem. Soc. Jpn., 1993, 66, 384.

37. a) T. Cartailler, W. Kunz, P. Turq, and M.-C. BellisentFunel, J. Phys.: Condens. Matter, 1991, 3, 9511. b) Y. Kameda and O. Uemura, Bull. Chem. Soc. Jpn., 1993, 66, 384. (c) Y. Kameda, H. Ebata, T. Usuki, and O. Uemura, Physica B, 1995, 213 - 214, 477. (d) Y. Kameda, N. Kodoh, S. Suzuki, T. Usuki, and O. Uemura, Bull. Chem. Soc. Jpn., 2001, 74, 1009.

38. P. R. Smirnov and V. N. Trostin, Russ. J. Gen. Chem., 2007, 77, 844.

39. (a) Y. P. Pukhovskii, D. V. Sakharov, and L. P. Safonova, $J$. Struct. Chem., 2002, 43, 284. (b) O. N. Kalugin, M. N. Volobuev, A. V. Ishchenko, and A. K. Adya, J. Nol. Liq., 2001, 91, 135. (c) A. K. Das and B. L. Tembe, J. Chem. Phys., 1999, 111, 7526. (d) A. K. Das and B. L. Tembe, $J$. Chem. Phys., 1998, 110, 2930.

40. (a) A. K. Soper and K. Weckström, Biophys. Chem., 2006, 124, 180. (b) A. Tongraar and B. M. Rode, Phys. Chem.
Chem. Phys., 2004, 6, 411. (c) S. Ramos, G. W. Neilson, A. C. Barnes, and P. Buchanan, J. Chem. Phys., 2005, 123, 214501.

41. O. Borodin, G. D. Smith, and W. Henderson, J. Phys. Chem. B, 2006, 110, 16879.

42. J. L. Nowinski, P. Lightfoot, and P. G. Bruce, J. Mater Chem., 1994, 4, 1579.

43. K. Matsumoto, R. Hagiwara, and O. Tamada, Solid State Sci., 2006, 8, 1103.

44. M. J. Monteiro, F. F. C. Bazito, L. J. A. Siqueira, M. C. C. Ribeiro, and R. M. Torresi, J. Phys. Chem. B, 2008, 112, 2102.

45. (a) N. Sieffert and G. Wipff, J. Phys. Chem. B, 2006, 110, 1106. (b) N. Sieffert and G. Wipff, J. Phys. Chem. B, 2006, 110, 19497. (b) N. Sieffert and G. Wipff, J. Phys. Chem. B, 2007, 111, 7253.

46. B. D. Shannon and C. T. Previtt, Acta Crystallogr., Sect. B, 1969, 25, 925 .

47. M. Deetlefs, C. Hardacre, M. Nieuwenhuyzen, A. A. H. Padua, O. Sheppard, and A. K. Soper, J. Phys. Chem. B, 2006, 110, 12055

48. J. N. C. Lopes, K. Shimizu, A. A. H. Pádua, Y. Umebayashi, S. Fukuda, K. Fujii, and S. Ishiguro, J. Phys. Chem. B, 2008, 112,1465 .

49. F. H. Allen, Acta Crystallogr., 2002, B58, 380.

50. (a) Y. Umebayashi, K. Matsumoto, Y. Mune, Y. Zhang, and S. Ishiguro, Phys. Chem. Chem. Phys., 2003, 5, 2552. (b) Y. Umebayashi, Y. Mune, T. Tsukamoto, Y. Zhang, and S. Ishiguro, J. Mol. Liq., 2005, 118, 45. (c) Y. Umebayashi, B. Mroz, M. Asada, K. Fujii, K. Matsumoto, Y. Mune, M. Probst, and S. Ishiguro, J. Phys. Chem. A, 2005, 109, 4862. (d) Y. Zhang, N. Watanabe, Y. Miyawaki, Y. Mune, K. Fujii, Y. Umebayashi, and S. Ishiguro, J. Solution Chem., 2005, 34, 1429. (e) Y. Zhang, N. Watanabe, Y. Umebayashi, and S. Ishiguro, J. Mol. Liq., 2005, 119, 167. (f) K. Fujii, Y. Umebayashi, R. Kanzaki, D. Kobayashi, R. Matsuura, and S. Ishiguro, J. Solution Chem., 2005, 34, 739. 